\title{
The effect of supplementing feed with vitamin C on the haematological indices of ducks and their offspring
}

\author{
H. Kontecka ${ }^{1,3}$, S. Nowaczewski ${ }^{1}$, J. Książkiewicz ${ }^{2}$ and A. Rosiński ${ }^{1}$ \\ ${ }^{1}$ The August Cieszkowski Agricultural University of Poznań, Department of Poultry Science \\ Witosa 45, 61-693 Poznań, Poland \\ ${ }^{2}$ National Research Institute of Animal Production, \\ Department of Waterfowl Breeding in Dworzyska \\ 62-035 Kórnik, Poland
}

(Received 29 July 2005; revised version 22 February 2006; accepted 5 July 2006)

\begin{abstract}
At the age of 24 weeks, 60 Pekin type ducks, line P66, were divided into 6 flocks (1 drake and 9 ducks). A control and an experimental group were formed, each comprising 3 flocks. Both groups were fed a standard diet, but that of the experimental group was supplemented with 500 $\mathrm{mg}$ vitamin $\mathrm{C} / \mathrm{kg}$. Ducks from the experimental group exhibited a significantly higher erythrocyte count (on average, by $0.16 \times 10^{12} / \mathrm{L}$ ) in blood collected in weeks 5,11 and 17 of the experiment. The haemoglobin level in the blood of birds from this group measured in week 17 was $0.73 \mathrm{mmol} / \mathrm{L}$ higher than in the control group. Both egg fertilization as well as duckling hatching from fertilized eggs obtained from ducks in the experimental group (on the third hatch) were higher, while the number of crippled ducklings was smaller. The erythrocyte count in the blood of one-day-old ducklings derived from the ducks fed vitamin $\mathrm{C}$-supplemented diets was significantly higher, on average, by $0.14 \times 10^{12} / \mathrm{L}$. In addition, in comparison with the control group, the haemoglobin level in the blood of ducklings derived from ducks in the experimental group and hatched from eggs set in weeks 4 and 11 of the experiment was 0.74 and $1.04 \mathrm{mmol} / \mathrm{L}$ higher, respectively. The ducklings derived from the experimental group of ducks and hatched from eggs set in week 18 of the experiment had a 2.5 percentage point higher haematocrit value.
\end{abstract}

KEY WORDS: vitamin C, duck, duckling, haematological indices, hatchability

\footnotetext{
${ }^{3}$ Corresponding author: e-mail: kontecka@jay.au.poznan.pl
} 


\section{INTRODUCTION}

In the course of the reproduction period, rearing conditions in housing facilities for ducks deteriorate considerably. The thickness of the wet, deep litter increases as does the air temperature inside the house, facilitating the development of pathogenic microorganisms. These factors are stressors that can exert a negative influence on production results (Jones, 1996; Klecker et al., 2002) as well as on the homeostasis of the ducks by, among others, changes in the values of haematological indices. Stress lowers the erythrocyte count, the haemoglobin concentration, and the haematocrit value in birds (Yahav and Hurvitz, 1996; Yahav, 1999). It was reported that due to stress, the total leucocyte count in the blood increased (Tymczyna et al., 1996; Kontecka et al., 1999), whereas that of lymphocytes, decreased (Maxwell and Robertson, 1995) and the heterophil-to-lymphocyte ratio increased (McFarlane and Curtis, 1989; Mitchell et al., cited by Maxwell, 1993). Moreover, some blood traits in ducks can be associated with reproduction results (Kontecka et al., 1995).

The addition of vitamin $\mathrm{C}$ to feeds for poultry can have a beneficial influence on the leucocyte count as well as on other haematological indices. In hens fed diets supplemented with vitamin C, Kontecka et al. (1997) reported higher erythrocyte counts, haemoglobin levels, and haematocrit values in comparison with the control group. Moreover, Zulkifli et al. (2000) found that vitamin C added to broiler feed alleviated the effects of stress. Consequently, the heterophil-to-lymphocyte ratio did not increase. There is no information in the available literature about effect of adding vitamin $\mathrm{C}$ to duck diets on their haematological indices.

The aim of this study was to investigate whether supplementing feeds with vitamin $\mathrm{C}$ can influence haematological indices in ducks during the reproductive period and in their offspring.

\section{MATERIAL AND METHODS}

During the reproduction period lasting from February to the end of July, a 26-week experiment was conducted at the Department of Waterfowl Breeding - Dworzyska, the National Research Institute of Animal Production. Sixty Pekin type ducks line P66, aged 24 weeks, were divided into 6 flocks ( 1 drake and 9 ducks) and kept in a windowless house on straw litter. A control and an experimental group, each comprising 3 flocks, were formed. Both groups were fed a standard diet containing $17.4 \%$ crude protein and 11.3 MJ of metabolizable energy per $\mathrm{kg}$. The diet was composed of, $\mathrm{g} / \mathrm{kg}$ : wheat 550 , barley 100 , soyabean oilmeal 160 , meat-and-bone meal 80 , dried grass 30 , fat concentrate 30, limestone 30, dicalcium phosphate 10 and vitamin-mineral premix 10 . The diet for the experimental group was supplemented with $500 \mathrm{mg}$ vitamin $\mathrm{C}$ per $\mathrm{kg}$. 
During the experimental period, blood was collected from all 54 females from the subcutaneous elbow vein (vena ulnaris cutanea) following a $12 \mathrm{~h}$ fast in weeks 5,11 and 17. In the course of the investigations, three hatches were carried out in weeks 4,11 and 18 of the experiment; all eggs collected during the preceding 5 days were set. The following numbers of eggs were set on the consecutive setting dates: 158 and 166, 128 and 117, and 71 and 157 for the control and experimental groups, respectively. After hatching, 36 one-day-old ducklings were selected from each group and blood was collected from their necks after decapitation.

Erythrocyte and leucocyte counts were made using Bürker's chambers under a microscope. The haemoglobin level was determined with the cyano-methaemoglobin method (Stankiewicz, 1973) and the haematocrit, by the micro-haematocrit method. Blood smears were stained by the Pappenheim method (Bomski, 1989) and then 100 consecutive leucocytes were counted under the microscope dividing them into granulocytes and agranulocytes. The significance of differences between means was verified by Student's t-test using the $\operatorname{SAS}^{\circledR}$ (v. 9.1) statistical package.

\section{RESULTS}

The ducks from the experimental group (Table 1) had a significantly higher erythrocyte count (on average, by $0.16 \times 10^{12} / \mathrm{L}$ ) in all blood tests, i.e. in weeks 5,11 and 17. In comparison with the control, the birds from the experimental group were also characterized by a higher haemoglobin level, albeit a statistically significant difference of $0.73 \mathrm{mmol} / \mathrm{L}$ was found only in the last blood test. Ducks from both groups did not differ with regard to the haematocrit value, although in week 11 the difference amounted to 1.5. In week 5 of the experiment, blood of the birds from the control group exhibited a significantly higher leucocyte count (by $5.5 \times 10^{9} / \mathrm{L}$ ), but during the next blood tests no significant differences between the groups were recorded.

Table 1. Effect of addition of vitamin $\mathrm{C}$ to feed on haematological indices of reproductive ducks

\begin{tabular}{|c|c|c|c|c|c|c|c|c|}
\hline \multirow{4}{*}{$\begin{array}{l}\text { Time, } \\
\text { week }\end{array}$} & \multicolumn{2}{|c|}{$\begin{array}{c}\text { Erythrocytes } \\
10^{12} / \mathrm{L} \\
\end{array}$} & \multicolumn{2}{|c|}{$\begin{array}{c}\text { Haemoglobin } \\
\mathrm{mmol} / \mathrm{L}\end{array}$} & \multicolumn{2}{|c|}{$\begin{array}{c}\text { Haematocrit } \\
\%\end{array}$} & \multicolumn{2}{|c|}{$\begin{array}{c}\text { Leucocytes } \\
10^{9} / \mathrm{L} \\
\end{array}$} \\
\hline & \multicolumn{8}{|c|}{ Dietary treatment } \\
\hline & control & vit. $C^{1}$ & control & vit. $C^{1}$ & control & vit. $C^{1}$ & control & vit. $C^{1}$ \\
\hline & \multicolumn{8}{|c|}{$\mathrm{n}=27$} \\
\hline 5 & $2.90^{*}$ & $3.05^{*}$ & 7.25 & 7.31 & 40.2 & 39.8 & $23.9^{*}$ & $18.4^{*}$ \\
\hline 11 & $2.85^{*}$ & $3.05^{*}$ & 7.20 & 7.34 & 36.3 & 37.8 & 18.8 & 18.7 \\
\hline 17 & $2.96^{*}$ & $3.09 *$ & $8.07 *$ & $8.80^{*}$ & 40.3 & 40.1 & 17.6 & 18.2 \\
\hline SEM & 0.04 & 0.04 & 0.19 & 0.19 & 0.59 & 0.58 & 1.23 & 1.20 \\
\hline
\end{tabular}

* - means in rows within trait are significantly different at $\mathrm{P} \leq 0.05$

${ }^{1} 500 \mathrm{mg}$ vit. $\mathrm{C} / \mathrm{kg}$ diet 
The control and the experimental groups failed to differ significantly with regard to the percentage of individual types of granulocytes (Table 2).

Table 2. Effect of addition of vitamin $\mathrm{C}$ to feed on the percentage of white blood cells and heterophil to lymphocyte $(\mathrm{H}: \mathrm{L})$ ratio in reproductive ducks

\begin{tabular}{|c|c|c|c|c|c|c|}
\hline \multirow{5}{*}{$\begin{array}{l}\text { Time, } \\
\text { week }\end{array}$} & \multicolumn{6}{|c|}{ Granulocytes, $\%$} \\
\hline & \multicolumn{2}{|c|}{ Basophils } & \multicolumn{2}{|c|}{ Eosinophils } & \multicolumn{2}{|c|}{ Heterophils } \\
\hline & \multicolumn{6}{|c|}{ Dietary treatment } \\
\hline & control & vit. $C^{1}$ & control & vit. $\mathrm{C}^{1}$ & control & vit. $C^{1}$ \\
\hline & \multicolumn{6}{|c|}{$\mathrm{n}=27$} \\
\hline 5 & 1.17 & 0.68 & 1.25 & 2.48 & 45.96 & 45.40 \\
\hline 11 & 1.67 & 1.92 & 2.83 & 3.08 & 47.33 & 48.76 \\
\hline 17 & 1.67 & 2.08 & 2.92 & 2.72 & 45.25 & 43.72 \\
\hline SEM & 0.29 & 0.28 & 0.54 & 0.52 & 2.05 & 2.01 \\
\hline \multirow{5}{*}{$\begin{array}{l}\text { Time, } \\
\text { week }\end{array}$} & \multicolumn{4}{|c|}{ Agranulocytes, \% } & \multirow{2}{*}{\multicolumn{2}{|c|}{$\mathrm{H}: \mathrm{L}$ ratio }} \\
\hline & Lyn & cytes & & cytes & & \\
\hline & \multicolumn{4}{|c|}{ Dietary treatment } & & \\
\hline & control & vit. $\mathrm{C}^{1}$ & control & vit. $\mathrm{C}^{1}$ & control & vit. $C^{1}$ \\
\hline & \multicolumn{6}{|c|}{$\mathrm{n}=27$} \\
\hline 5 & 50.96 & 48.32 & 2.84 & 3.12 & 0.99 & 0.95 \\
\hline 11 & 46.04 & 43.60 & 2.13 & 2.24 & 1.11 & 1.24 \\
\hline 17 & 47.54 & 48.76 & 2.63 & 2.72 & 0.93 & 0.95 \\
\hline SEM & 2.05 & 2.00 & 0.36 & 0.35 & 0.09 & 0.09 \\
\hline
\end{tabular}

* - means in rows within trait are significantly different at $\mathrm{P} \leq 0.05$

${ }^{1} 500 \mathrm{mg}$ vit. $\mathrm{C} / \mathrm{kg}$ diet

Moreover, the two groups did not differ $(\mathrm{P} \leq 0.05)$ with regard to the percentage of lymphocytes or as to the heterophil-to-lymphocyte ratio.

In the third hatch, the ducks from the experimental group had significantly more fertilized eggs (by 16.5 percentage points) and duckling hatches from fertilized eggs (by 23.6 percentage points) (Table 3). In the same hatch, the control group had a significantly higher (by 9.9 percentage points) hatching of crippled ducklings. Feed consumption in the groups was not controlled in the course of the experiment, but the ducks fed the vitamin C-supplemented diets consumed more feed.

Table 3. Effect of addition of vitamin $\mathrm{C}$ to feed on egg fertilization and hatchability results in ducks

\begin{tabular}{|c|c|c|c|c|c|c|}
\hline \multirow{3}{*}{ Time of hatch } & \multirow{2}{*}{\multicolumn{2}{|c|}{ Egg fertilization, $\%$}} & \multirow{2}{*}{\multicolumn{2}{|c|}{$\begin{array}{l}\text { Hatching of fertilized } \\
\text { eggs, \% } \\
\text { Dietary treatment }\end{array}$}} & \multicolumn{2}{|c|}{$\begin{array}{c}\text { Crippled ducklings, } \\
\%\end{array}$} \\
\hline & & & & & & \\
\hline & control & vit. $\mathrm{C}^{1}$ & control & vit. $\mathrm{C}^{1}$ & control & vit. $\mathrm{C}^{1}$ \\
\hline \multirow[t]{3}{*}{ Eggs set in: week } & 81.3 & 88.2 & 88.3 & 88.9 & 1.5 & 1.3 \\
\hline & 83.8 & 91.5 & 87.9 & 85.7 & 1.0 & 0.9 \\
\hline & $54.2 *$ & $70.7 *$ & $52.2 *$ & $75.8^{*}$ & $10.7^{*}$ & $0.8^{*}$ \\
\hline SEM & 4.46 & 4.46 & 5.41 & 5.41 & 2.78 & 2.78 \\
\hline
\end{tabular}

* - means in rows within trait are significantly different at $\mathrm{P} \leq 0.05$

${ }^{1} 500 \mathrm{mg}$ vit. $\mathrm{C} / \mathrm{kg}$ diet 


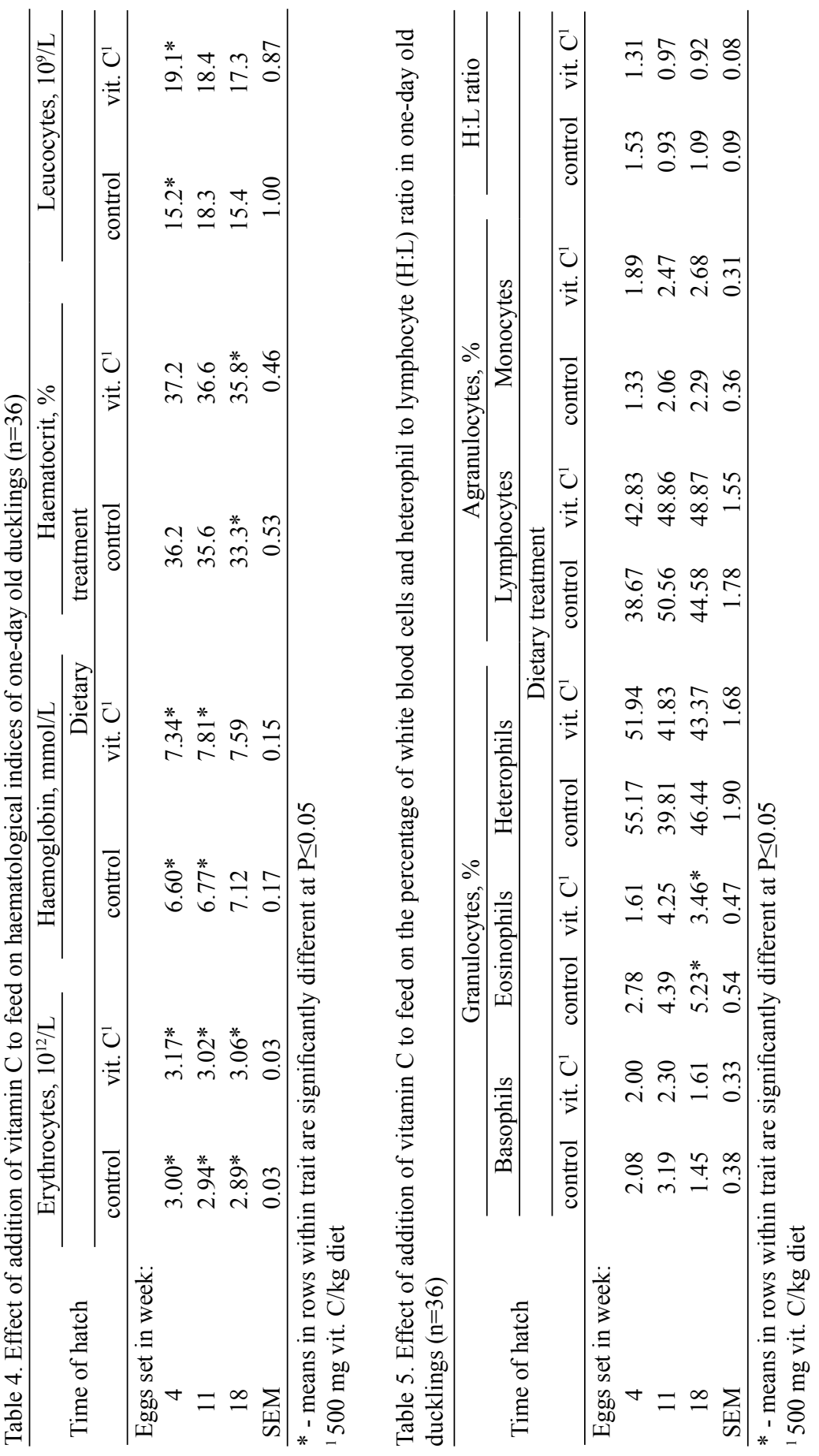


One-day-old ducklings derived from parents in the experimental group were characterized by a significantly higher erythrocyte count (on average by $0.14 \times$ $10^{12} / \mathrm{L}$ ) in all three hatches (Table 4). In addition, the ducklings from the first and second hatches were characterized by a higher haemoglobin level $(0.74$ and 1.04 $\mathrm{mmol} / \mathrm{L}$, respectively) when compared with the control group. In the third hatch, the haematocrit value in the group of ducklings derived from the experimental group was found to be significantly higher (by 2.5 percentage points). Ducklings derived from the control group had a $3.9 \times 10^{9} / \mathrm{L}$ lower $(\mathrm{P} \leq 0.05)$ leucocyte count in the first hatch.

On the other hand, ducklings derived from the parents of both groups did not differ significantly with regard to the percentage of basophils, heterophils, lymphocytes, monocytes, as well as to the heterophil-to-lymphocyte ratio in any of the three hatches (Table 5). The only exception was the percentage of eosinophils, which was higher in the blood of ducklings from the third hatch derived from the control ducks.

\section{DISCUSSION}

The erythrocyte count in the blood of ducks fed the vitamin C-supplemented diet $(500 \mathrm{mg} / \mathrm{kg}$ vitamin C) was higher in all blood tests, but the haemoglobin level in this group of birds was higher only in the third blood test. Kontecka et al. (1997) reported a higher (by $0.56 \times 10^{12} / \mathrm{L}$ ) erythrocyte count in 30 -week-old laying hens fed diets supplemented with $200 \mathrm{mg} / \mathrm{kg}$ vitamin $\mathrm{C}$ in comparison with birds from the control group. According to Torgowski and Kontecka (1998), pheasants fed diets supplemented with vitamin $\mathrm{C}$ and iron had, in the middle and towards the end of the reproductive period, a higher erythrocyte count and higher (on average, by $0.99 \mathrm{mmol} / \mathrm{L}$ ) haemoglobin level. Also Al-Taweil and Kassab (cited by Traş et al., 2000) reported a higher haemoglobin level in broiler chickens fed vitamin C-supplemented diets $(450 \mathrm{mg} / \mathrm{kg})$ in comparison with controls. Higher levels of egg fertilization and better hatching results in the group of ducks fed vitamin C-supplemented diets could have been associated with the increased erythrocyte count in the blood of these birds. Kontecka et al. (1995) found a positive correlation between the number of erythrocytes and egg fertilization $\left(r_{p}=0.355\right)$ and duckling hatchings $\left(r_{p}=0.443\right)$.

No difference was found the present experiment in the haematocrit value between ducks fed diets with or without vitamin C. Similar results in broiler chickens were reported by Hassanzadeh-Ladmakhi et al. (1997). In our study, ducks fed vitamin C-supplemented diets had a lower leucocyte count in the first blood test. On the other hand, in hens and pheasants, Kontecka et al. (1997) and 
Torgowski and Kontecka (1998) did not find differences in the leucocyte counts between birds fed vitamin C-supplemented diets and controls.

Satterlee et al. (1989) reported a smaller number of heterophils and a higher one of lymphocytes in the blood of broiler chickens fed vitamin C-supplemented diets and examined $8 \mathrm{~h}$ before slaughter, as compared with birds from the control group. Hence the value of the heterophil-to-lymphocyte ratio in this group of chickens was lower. On the other hand, Gross $(1988 \mathrm{a}, \mathrm{b})$ reported a lower heterophil-tolymphocyte ratio in chickens exposed to a short-term thermal stress and low air temperatures and fed vitamin C-supplemented diets. In the present study, however, no effect of vitamin $\mathrm{C}$ was found on the heterophil and lymphocyte counts or on the heterophil-to-lymphocyte ratio in the blood of ducks. This could have been caused by the long-term effect of the deteriorating environmental conditions on the organisms of ducks. Maxwell et al. (1992) and Maxwell (1993) showed that long-term exposure to stress reduced the number of heterophils and increased the numbers of basophils and monocytes in birds. Also Kontecka et al. (1997) found a considerable increase in the proportion of basophils, eosinophils and monocytes 5 weeks after the withdrawal of vitamin $\mathrm{C}$ from diets fed to hens reared under poor environmental conditions. Differences between the control and experimental groups in the heterophil-to-lymphocyte ratio were not found. The observed higher erythrocyte counts, haemoglobin levels, and haematocrit values in the blood of the one-day-old ducklings from the experimental group could be indicative of a positive impact of the feeding of reproductive ducks with vitamin C-supplemented diets. No significant differences between ducklings derived from the parents from the vitamin $\mathrm{C}$-supplemented and control groups regarding the percentage of granulocytes and agranulocytes were observed, however. A more comprehensive discussion of our results is impossible due to the lack of literature data on this subject.

\section{CONCLUSIONS}

It can be concluded that ducks fed diets supplemented with $500 \mathrm{mg} / \mathrm{kg}$ vitamin $\mathrm{C}$ were characterized byhigher erythrocyte counts and higher haematocrit values. Our investigations failed to show the impact of this vitamin on the leucocyte profile, in particular, on the heterophil-to-lymphocyte ratio, however. The results of egg fertilization and hatchability were better in ducks fed vitamin Csupplemented diets. One-day-old ducklings derived from the ducks fed vitamin $\mathrm{C}$-supplemented diets had higher erythrocyte counts, haemoglobin levels, and haematocrit values.

Producers can be encouraged to add vitamin $\mathrm{C}$ to duck feed, especially during the final period of reproduction. 


\section{REFERENCES}

Bomski A., 1989. Basal Haematological Investigations (in Polish). PZWL, Warszawa, pp. 56-182

Gross W.B., 1988a. Effect of ascorbic acid on the mortality of Leghorn-type chickens due to overheating. Avian Dis. 32, 561-562

Gross W.B., 1988b. Effect of ascorbic acid on antibody response of stressed and unstressed chickens. Avian Dis. 32, 483-485

Hassanzadeh-Ladmakhi M., Buys N., Dewil E., Rahimi G., Decuypere E., 1997. The prophylactic effect of vitamin $\mathrm{C}$ supplementation on broiler ascites incidence and plasma thyroid hormone concentration. Avian Pathol. 26, 33-44

Jones R.B., 1996. Fear and adaptability in poultry: insights, implications and imperatives. World Poultry Sci. J. 52, 131-174

Klecker D., Havliček L., Zeman L., 2002. Heat stress in laying hens. Rocz. Nauk. Zoot., Supl. 16, 127-130

Kontecka H., Książkiewicz J., Cegielska E., 1995. Changes in the values of haematological indices in laying season and their connection with reproduction traits in ducks. In: Proceedings of $10^{\text {th }}$ European Symposium on Waterfowl, Halle (Germany), pp. 269-272

Kontecka H., Książkiewicz J.M., Nogowski L., 1999. Effects of different stressors on laying rate and selected blood indices in reproductive ducks. J. Anim. Feed Sci. 8, 63-72

Kontecka H., Witkiewicz K., Sobczak J., 1997. Effect of vitamin C addition to feed on production and haematological indices in laying hens (in Polish). Prz. Hod., Zesz. Nauk. PTZ 32, 139-145

Maxwell M.H., 1993. Avian blood leucocyte responses to stress. World Poultry Sci. J. 49, 34-43

Maxwell M.H., Hocking P.M., Robertson G.W., 1992. Differential leucocyte response to various degrees of food restriction in broilers, turkeys and ducks. Brit. Poultry Sci. 33, 177-187

Maxwell M.H., Robertson G.W., 1995. The avian basophilic leukocyte: a review. World Poultry Sci. J. 51, 307-325

McFarlane J.M., Curtis S.E., 1989. Multiple concurrent stressors in chicks. 3. Effects on plasma corticosterone and the heterophil to lymphocyte ratio. Poultry Sci. 68, 522-527

Satterlee D.G., Aquilera-Quintana I.A., Munn B.J., Krautmann B.A., 1989. Vitamin C amelioration of the adrenal stress response in broiler chickens being prepared for slaughter. Comp. Biochem. Physiol. Pt A 94, 569-574

Stankiewicz W., 1973. Veterinary Haematology (in Polish). PWRiL, Warszawa, pp. 423

Torgowski J., Kontecka H., 1998. Effect of the addition of vitamin C and iron to pheasant (Phasianus colchicus) diets on their production and haematological indices (in Polish). Rocz. AR Poznań 302, Zoot. 50, 235-242

Traş B., Inal F., Baş A.L., Altunok V., Elmas M., Yazar E., 2000. Effects of continuous supplementations of ascorbic acid, aspirin, vitamin E and selenium on some haematological parameters and serum superoxide dismutase level in broiler chickens. Brit. Poultry Sci. 41, 664-666

Tymczyna L., Saba L., Bis-Wencel H., 1996. Effect of high ammonia concentration in the air on hematological and physiological indices in slaughter chickens (in Polish). Rocz. Nauk. Zoot. 23, 263-270

Yahav S., 1999. The effect of constant and diurnal cyclic temperatures on performance and blood system of young turkeys. J. Therm. Biol. 24, 71-78

Yahav S., Hurwitz S., 1996. Induction of thermotolerance in male broiler chickens by temperature conditioning at an early age. Poultry Sci. 75, 402-406

Zulkifli I., Che Norma M.T., Chong C.H., Loh T.C., 2000. The effects of crating and road transportation on stress and fear responses of broiler chickens treated with ascorbic acid. Arch. Geflügelk. 65, 33-37 